\title{
Progesterone impairs cell respiration and suppresses a compensatory increase in glucose transport in isolated rat skeletal muscle: a non-genomic mechanism contributing to metabolic adaptation to late pregnancy?
}

\author{
F. Gras • B. Brunmair • L. Quarré • Z. Szöcs • \\ W. Waldhäusl $•$ C. Fürnsinn
}

Received: 8 July 2007 / Accepted: 15 August 2007 / Published online: 12 October 2007

(C) Springer-Verlag 2007

\begin{abstract}
Aims/hypothesis The aim of the study was to gain better insight into the mechanisms responsible for impaired glucose metabolism during late pregnancy. We explored the direct effects of progesterone on glucose metabolism of skeletal muscle.

Methods Specimens of skeletal muscle from untreated rats were incubated with progesterone and rates of substrate fluxes through the various pathways of glucose metabolism were analysed.

Results Progesterone dose-dependently reduced the rates of glucose and pyruvate oxidation (insulin-stimulated rates after $5 \mathrm{~h}$ of exposure to 1 and $10 \mu \mathrm{mol} / \mathrm{l}$ progesterone: glucose oxidation, $-6 \pm 4 \%$, NS, and $-39 \pm 4 \%, p<0.001$; pyruvate oxidation, $-28 \pm 2 \%$ and $-55 \pm 4 \%, p<0.001$ each) and increased lactate release $(+28 \pm 4 \%$ and $+58 \pm 9 \%$,
\end{abstract}

Electronic supplementary material The online version of this article (doi: 10.1007/s00125-007-0836-4) contains supplementary material, which is available to authorised users.

F. Gras · B. Brunmair $\cdot$ L. Quarré · Z. Szöcs $\cdot$ W. Waldhäusl •

C. Fürnsinn $(\bowtie)$

Department of Medicine III, Division of Endocrinology

and Metabolism, Medical University of Vienna,

Währinger Gürtel 18-20,

1090 Vienna, Austria

e-mail: clemens.fuernsinn@meduniwien.ac.at

Present address:

F. Gras

Department of Trauma, Hand and Reconstructive Surgery,

University Hospital Jena,

Jena, Germany $p<0.005$ each), which indicated inhibition of mitochondrial respiratory function. Impairment of cell respiration, e.g. by the specific inhibitor rotenone, is known to trigger a compensatory increase in glucose transport, but this response was blunted in the case of progesterone (change of glucose transport in response to $10 \mu \mathrm{mol} / \mathrm{l}$ progesterone vs $60 \mathrm{nmol} / \mathrm{l}$ rotenone, both causing a reduction in glucose oxidation by $-39 \%$ : progesterone, $+14 \pm 8 \%$ vs rotenone, $+84 \pm 23 \%$, $p<$ $0.03)$. Further experiments dealt with the underlying mechanisms and revealed a rapid mode of action $(50 \mu \mathrm{mol} / \mathrm{l}$ progesterone, reduction in insulin-stimulated glucose oxidation after 30 min: $-29 \pm 7 \%, p<0.01$ ) not affected by blockers of gene expression or the nuclear progesterone receptor.

Conclusions/interpretation Progesterone inhibits cell respiration and at the same time suppresses a compensatory increase in glucose transport, causing cellular carbohydrate deficiency in isolated rat skeletal muscle. This effect is mediated by a direct, rapid and non-genomic mechanism and could contribute to pregnancy-associated changes in glucose homeostasis.

Keywords Glucose metabolism · Glucose oxidation . Glucose transport - Glycogen synthesis · Progesterone . Progesterone receptor membrane component 1 .

Skeletal muscle

\section{Introduction}

Late pregnancy is associated with reduced insulin-stimulated glucose disposal, increased hepatic glucose release and elevated gluconeogenesis $[1,2]$, which in predisposed women can lead to gestational diabetes. Little is known about the 
precise mechanisms and hormones responsible for these adaptations, which could serve to shift fuel substrate from maternal tissues to the fetus. While several peptide and steroid hormones could make a contribution, a strong line of evidence points at a predominant role of circulating progesterone, which during the course of pregnancy increases in tight association with the reduction in insulin-stimulated glucose disposal $[3,4]$. The presumptive function of progesterone as a physiological modulator of glucose homeostasis is supported by parallel fluctuations of endogenous plasma progesterone concentrations and insulin sensitivity during the human menstrual cycle $[5,6]$, as well as by a correlation between the plasma concentrations of progesterone and glucose in female mice studied randomly during their cycle [7]. Accordingly, insulin sensitivity is reduced in women taking progestins $[8,9]$, while progesterone administration to rodents blunts the hypoglycaemic action of insulin and accelerates the obesity-associated deterioration of glucose homeostasis $[7,10]$.

The precise mechanisms via which progesterone exerts its effects on glucose metabolism are not known, but skeletal muscle is predominantly responsible for reductions in insulin-stimulated glucose disposal associated with human pregnancy and with chronic progesterone and oestradiol treatment in dogs $[11,12]$. Whereas effects of progesterone on pancreatic beta cells, hepatocytes and adipocytes [7, 13-15] are likely to influence glucose metabolism of skeletal muscle indirectly, the possible contribution of direct actions on muscle has received little attention. Based on promising results reported two decades ago $[10,16]$, the present study set out to close this gap in knowledge. Using isolated tissue specimens, an approach that excludes indirect actions via other organs, the experiments aimed to thoroughly explore and analyse the effects of progesterone on glucose metabolism of rat skeletal muscle.

\section{Methods}

Rats

Sprague-Dawley rats (male, unless stated otherwise) were purchased from the breeding facilities of the Medical University of Vienna (Himberg, Austria). They were kept in an artificial $12 \mathrm{~h}$ light-dark cycle at constant room temperature and provided with conventional laboratory diet and tap water ad libitum. At an age of 5-7 weeks (approximately $150 \mathrm{~g}$ body weight) food, but not water, was withdrawn overnight and rats were killed by cervical dislocation between 09:00 and 10:00 hours. All experiments were performed according to local law and to the principles of good laboratory animal care.
Muscle incubation

Pretreatment period Immediately after killing, two longitudinal strips of soleus or extensor digitorum longus muscle per leg were prepared, weighed (approximately $25 \mathrm{mg}$ per strip) and tied under tension on stainless steel clips [17]. Using procedures established at our laboratory [18], muscles were immediately put into Erlenmeyer flasks coated with BlueSlick solution (Serva, Heidelberg, Germany) and provided with Cell Culture Medium 199 (pH 7.35, 5.5 mmol/1 glucose; Sigma, St. Louis, MO, USA) containing supplements of $5 \mathrm{mmol} / 1$ HEPES, 25,000 U/1 penicillin $\mathrm{G}, 25 \mathrm{mg} / \mathrm{l}$ streptomycin and $0.2 \mathrm{mg} / 1$ ciprofloxacine. Other additions depended on the specific experiment and included progesterone or other steroids (from Steraloids, Newport, RI, USA) dissolved in ethanol, and rotenone, RU486, actinomycin D or cycloheximide (all from Sigma) dissolved in DMSO.

For the determination of fatty acid oxidation, the medium was additionally supplemented with $0.3 \%(w / v)$ fatty acid-free BSA and $300 \mu \mathrm{mol} / \mathrm{l}$ palmitate dissolved in ethanol. These additions were also used in experiments dealing with actinomycin D or cycloheximide, because their activities as inhibitors of transcription and protein synthesis, respectively, are documented under such conditions [18]. The final concentrations of DMSO and ethanol never exceeded 0.1 and $0.35 \%(v / v)$, respectively, and were always identical with those in the respective control. All incubations were under a continuous atmosphere of $95 \%$ $\mathrm{O}_{2}-5 \% \mathrm{CO}_{2}$. Prolonged pretreatment for $4 \mathrm{~h}$, as applied in most experiments, was in flasks containing three muscle specimens and $15 \mathrm{ml}$ medium. Shorter pretreatment was in flasks containing $3 \mathrm{ml}$ medium and one muscle strip.

Measurement period After pretreatment, muscles were transferred into identical medium (one muscle strip in $3 \mathrm{ml}$ medium per flask) additionally supplemented with trace amounts of $\mathrm{d}-\left[\mathrm{U}_{-}{ }^{14} \mathrm{C}\right]$ glucose, $\mathrm{d}-\left[\mathrm{U}_{-}{ }^{14} \mathrm{C}\right]$ palmitate, $\left[\mathrm{U}-{ }^{14} \mathrm{C}\right]$ methionine, $\left[{ }^{14} \mathrm{C}_{1}\right]$ pyruvic acid or 2-deoxy-d$\left[{ }^{3} \mathrm{H}_{2,6}\right]$ glucose plus d-[U- $\left.{ }^{14} \mathrm{C}\right]$ sucrose (all from Amersham Pharmacia Biotech UK, Little Chalfont, UK), and, if stated, with human insulin (Actrapid; Novo, Bagsvaerd, Denmark). Unless stated otherwise, the measurement period was $1 \mathrm{~h}$, after which muscles were quickly removed from the flasks, blotted and frozen in liquid nitrogen.

Analyses ${ }^{14} \mathrm{CO}_{2}$ produced from radiolabelled glucose, palmitate or pyruvic acid was trapped with a solution containing methanol and phenethylamine $(1: 1$; referred to as glucose, palmitate or pyruvate oxidation) [19]. Rates of glucose and palmitate oxidation are given in mole per gram per hour as calculated from their specific activity in the incubation medium, whereas the oxidation rate of pyruvate, 
which was not present in the incubation medium, is given in counts per minute per gram per hour. For the measurement of glycogen storage, frozen muscle strips were lysed in $1 \mathrm{~mol} / 1 \mathrm{KOH}$ at $70^{\circ} \mathrm{C}$ and the net rate of glucose incorporation into glycogen was calculated from the conversion of $\left[{ }^{14} \mathrm{C}\right]$ glucose into $\left[{ }^{14} \mathrm{C}\right]$ glycogen (referred to as glycogen synthesis) [19]. The glycogen content at the end of the experiment was determined by degrading glycogen in the muscle lysate to glucose with amyloglucosidase, followed by the measurement of glucose with an enzymatic kit (Human, Taunusstein, Germany). Rates of lactate release were calculated from lactate accumulated in the incubation medium as measured with a spectrophotometric lactate dehydrogenase method [20]. Intracellular accumulation of 2-deoxy-d- $\left[{ }^{3} \mathrm{H}_{2,6}\right]$ glucose was determined as described [19] and was corrected using $\mathrm{d}-\left[\mathrm{U}_{-}{ }^{14} \mathrm{C}\right]$ sucrose as a marker for the extracellular space (referred to as glucose transport). The net rate of methionine incorporation into protein was calculated from the conversion of $\left[{ }^{14} \mathrm{C}\right]$ methionine into ${ }^{14} \mathrm{C}$-labelled protein using muscle strips lysed in $1 \mathrm{~mol} / \mathrm{l} \mathrm{NaOH}$ (referred to as protein synthesis) [18]. For the determination of the cellular energy charge, muscle strips were extracted with $3 \mathrm{~mol} / \mathrm{l}$ perchloric acid. ATP and phosphocreatine were measured spectrophotometrically after neutralisation with $\mathrm{KOH}[21]$.

mRNA encoding progesterone receptor membrane component 1

To examine the tissue-specific expression of Pgrmcl, the gene encoding progesterone receptor membrane component 1, tissue specimens were isolated immediately after killing and put into of RNAlater solution (Ambion, Austin, TX, USA; $1 \mathrm{ml} / 100 \mathrm{mg}$ ). Approximately $50 \mathrm{mg}$ tissue were transferred into RNAzol B solution (Tel-Test, Friendswood, TX, USA) and homogenised for $1 \mathrm{~min}$, before total RNA was isolated according to manufacturer's instructions. RNA content of the extract was determined photometrically (ratio $260: 280 \mathrm{~nm}>1.9)$ and checked for quality by $1.5 \%$ agarose gel electrophoresis. One microgram of isolated RNA was treated with RNAse-free DNAse (Invitrogen, Carlsbad, CA, USA) and reverse transcribed into cDNA (Superscript II; Invitrogen) using poly $\mathrm{T}-\mathrm{A} / \mathrm{-} / \mathrm{-}-\mathrm{G}$ priming according to manufacturer's instruction. Expression of mRNA encoding for Rattus norvegicus progesterone receptor membrane component 1 was examined by PCR (forward primer: AGGTGTTCGACGTGACCAAAGG; reverse primer CACTCTTCCGAGCAGCCTCAC) and visualised by $1 \%$ agarose gel electrophoresis including a molecular weight marker ( $\Phi$ X174 RF DNA/HaeIII fragments; Invitrogen). The predicted sequence of the detected transcript was analysed and confirmed by VBC-Genomics (Vienna, Austria).
Progesterone receptor membrane component 1 protein

Tissue lysates were prepared and checked for protein content. Thirty micrograms of protein were subjected to $12 \%$ SDS-PAGE and transferred to nitrocellulose mem-
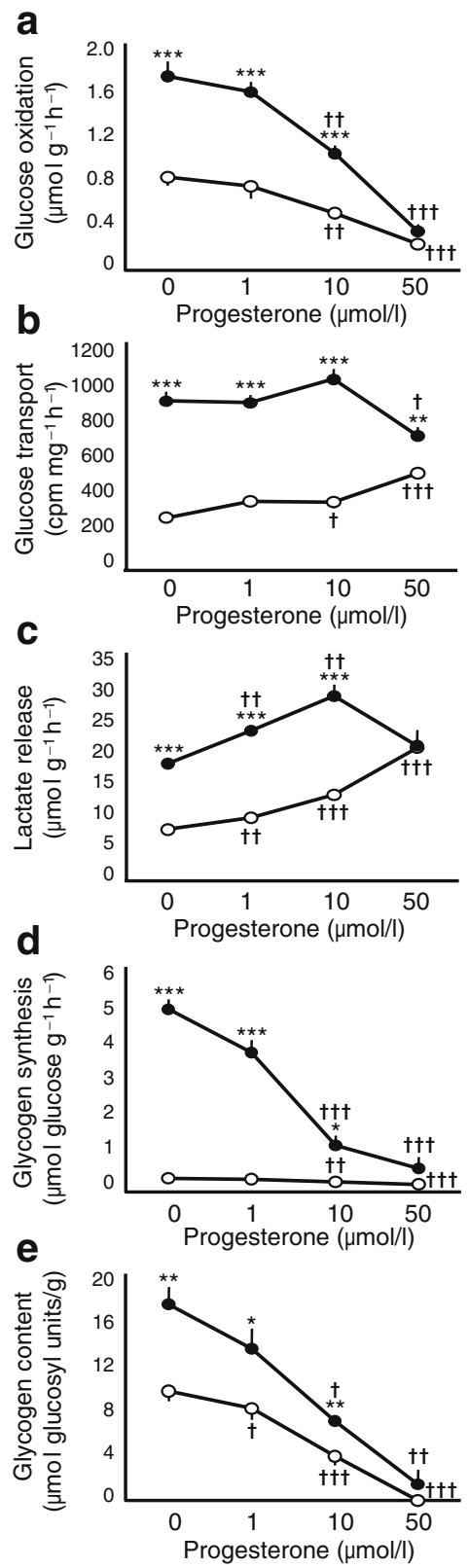

Fig. 1 Progesterone action on glucose metabolism of rat soleus muscle. Strips of rat soleus muscle were incubated for $5 \mathrm{~h}$ with 1,10 or $50 \mu \mathrm{mol} / \mathrm{l}$ progesterone. Basal (open circles) or insulin-stimulated (closed circles; $25 \mathrm{nmol} / \mathrm{l}$ ) rates of glucose oxidation (a), glucose transport (b), lactate release (c) and net glycogen synthesis (d) were measured during the last hour. Glycogen content (e) was determined at the end of the experiment. Data are given as means \pm SEM (some SEMs are hidden by symbols); ${ }^{*} p<0.05 ; * * p<0.01 ; * * * p<0.001$ vs basal conditions. $p<0.05$; $p<0.01 ; \uparrow p<0.001$ vs absence of progesterone 


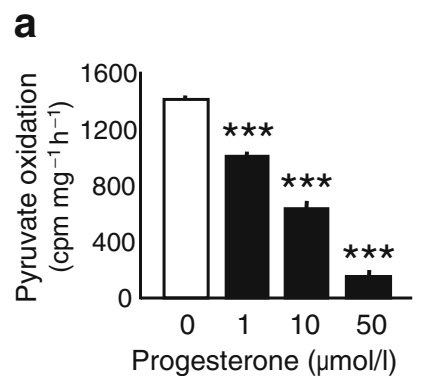

b

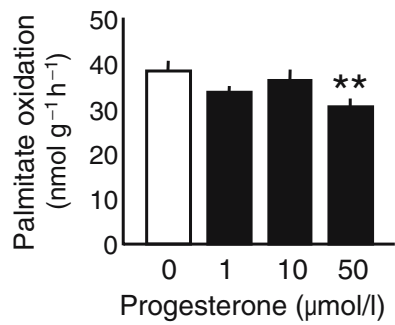

C

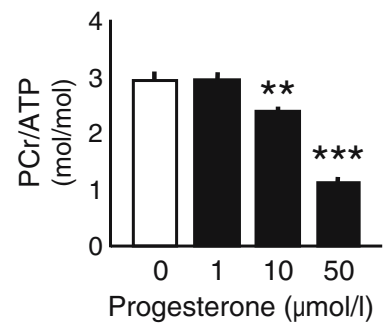

Fig. 2 Progesterone action on pyruvate and palmitate oxidation, and on energy charge. Strips of rat soleus muscle were incubated for $5 \mathrm{~h}$ with 1,10 or $50 \mu \mathrm{mol} / 1$ progesterone. Insulin-stimulated $(25 \mathrm{nmol} / \mathrm{l})$ rates of pyruvate oxidation (a) and palmitate oxidation (b) were

branes as described previously [22]. They were then exposed overnight at $4^{\circ} \mathrm{C}$ to antisera 7790 or $\mathrm{T} 2$ for progesterone receptor membrane component 1 protein $(28 \mathrm{kDa})$, which were generously provided by M. Lösel (University of Heidelberg, Germany). Then, they were exposed to the secondary antibody (peroxidase-labelled anti-rabbit IgG from Amersham) for $60 \mathrm{~min}$ at room temperature. The bands were visualised using Super Signal System from Pierce (Rockford, IL, USA) and Kodak XAR5-Omat films (Kodak, Rochester, NY, USA).

\section{Statistics}

According to the exploratory character of the study, statistics were used in a descriptive sense. Results are given as means \pm SEM, differences were analysed by paired or unpaired two-tailed Student's $t$ tests with $p<0.05$ considered as significant.

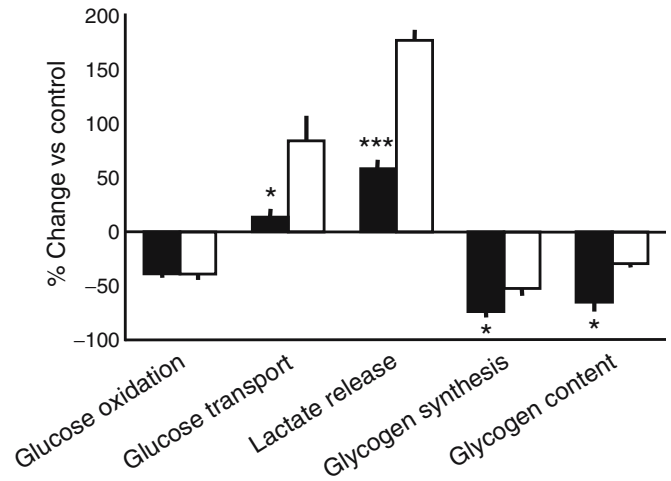

Fig. 3 Comparison of concentrations of progesterone and rotenone that cause the same impairment of glucose oxidation. Strips of rat soleus muscle were incubated for $5 \mathrm{~h}$ with $10 \mu \mathrm{mol} / \mathrm{l}$ progesterone (data adapted from Fig. 1; closed bars) or with $60 \mathrm{nmol} / 1$ rotenone (open bars). Insulin-stimulated $(25 \mathrm{nmol} / \mathrm{l})$ rates of glucose oxidation, glucose transport, lactate release and net glycogen synthesis were measured during the last hour. Glycogen content was determined at the end of the experiment. Data are given as percentage change vs an intra-individual control as means $\pm \mathrm{SEM} ;{ }^{*} p<0.05$; ${ }^{* * *} p<0.001$ for progesterone vs rotenone measured during the last hour. $\mathbf{c}$ Phosphocreatine/ATP ratio (PCr/ATP) after $5 \mathrm{~h}$ of progesterone exposure. Data are given as means $\pm \mathrm{SEM}$; ${ }^{* *} p<0.01 ; * * * p<0.001$ vs absence of progesterone

\section{Results}

Progesterone action on isolated rat muscle

Dependence on dose and insulin In isolated soleus muscle from male rats, progesterone shifted basal glucose metabolism from the aerobic to the anaerobic pathway, which was reflected by a dose-dependent reduction of basal rates of glucose oxidation, accompanied by increasing rates of lactate release (Fig. 1; ratio of basal glucose oxidation/ lactate production, arbitrary units: control, $1.00 \pm 0.07$; $1 \mu \mathrm{mol} / \mathrm{l}$ progesterone, $0.81 \pm 0.07, p<0.05 ; 10 \mu \mathrm{mol} / \mathrm{l}$ progesterone, $0.43 \pm 0.04, p<0.001 ; 50 \mu \mathrm{mol} / 1$ progesterone, $0.13 \pm$ $0.01, p<0.001)$. This was associated with an increase in glucose transport and a decrease in net glycogen synthesis (i.e. glycogen depletion), which obviously reflected increased carbohydrate requirements to compensate for the much lower yield of ATP from anaerobic than aerobic metabolism.

The same shift from the aerobic towards the anaerobic pathway was observed for insulin-stimulated glucose metabolism (ratio of insulin-stimulated glucose oxidation/lactate production, arbitrary units: control, $1.00 \pm 0.07 ; 1 \mu \mathrm{mol} / 1 \mathrm{pro}-$ gesterone, $0.72 \pm 0.04, p<0.05 ; 10 \mu \mathrm{mol} / \mathrm{l}$ progesterone, $0.39 \pm$ $0.03, p<0.001 ; 50 \mu \mathrm{mol} / 1$ progesterone, $0.19 \pm 0.09$, $p<0.001$ ), but at variance with what was seen under basal conditions, glucose transport and lactate release decreased markedly between 10 and $50 \mu \mathrm{mol} / \mathrm{l}$ progesterone (Fig. 1). The pattern of response was basically the same in extensor digitorum longus muscle and in soleus muscle from female rats and, hence, the described actions of progesterone were, at least largely, independent of sex and fibre composition [Electronic Supplementary Material (ESM) Fig. 1].

As the observed response suggested impairment of cell respiration, we next measured the effect of progesterone on pyruvate oxidation. A marked decrease of pyruvate oxidation indicated that progesterone inhibited cell respiration downstream of glycolysis, i.e. within the mitochondrion (Fig. 2a). Additions of $0.3 \%(w / v)$ BSA plus $300 \mu \mathrm{mol} / 1$ 


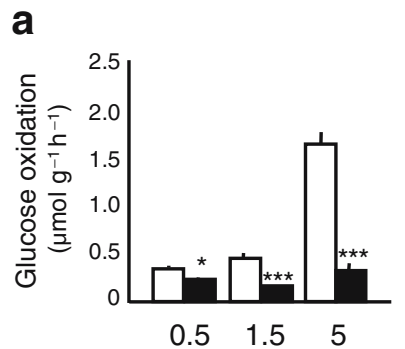

Total exposure time (h) b

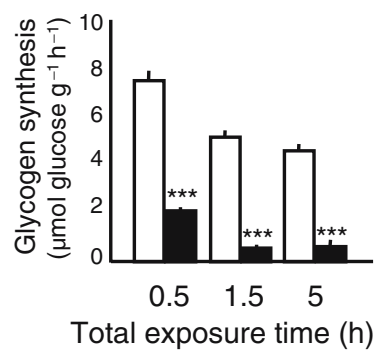

Fig. 4 Time dependence of progesterone action. Strips of rat soleus muscle were incubated for $0.5,1.5$ or $5 \mathrm{~h}$ without or with $50 \mu \mathrm{mol} / 1$ progesterone (open and closed bars, respectively). Rates of glucose oxidation (a), net glycogen synthesis (b) and lactate release (d) were measured during the last hour under stimulation with $25 \mathrm{nmol} / \mathrm{l}$ insulin

palmitate to the incubation medium, which are prerequisites for measuring the rate of palmitate oxidation, very modestly blunted the effect of progesterone on muscle glucose metabolism, presumably due to binding of progesterone to BSA and/or the availability of an alternative fuel substrate (ESM Table 1). Under these conditions, palmitate oxidation was also reduced by progesterone (Fig. 2b), but to a much lesser extent than glucose oxidation (at $50 \mu \mathrm{mol} / 1$ progesterone: palmitate oxidation, $-17 \pm 6 \%$, vs glucose oxidation, $-49 \pm 6 \% ; p=0.002)$. This result excludes a progesteroneinduced increase in lipid utilisation as the cause of reduced glucose oxidation. In line with impaired mitochondrial fuel oxidation, progesterone dose-dependently reduced the ratio of phosphocreatine/ATP, a measure of the cellular energy charge (Fig. 2c), and the energy-dependent process of protein synthesis was also reduced by a high concentration of progesterone (nmol methionine incorporated $\mathrm{g}^{-1} \mathrm{~h}^{-1}$ : control, $31 \pm 2 ; 1 \mu \mathrm{mol} / 1$ progesterone, $36 \pm 2$, NS; $10 \mu \mathrm{mol} / 1$ progesterone $29 \pm 3$, NS; $50 \mu \mathrm{mol} / 1$ progesterone, $17 \pm 1$, $p<0.001)$.

In spite of such obvious inhibition of cell respiration, the effect of progesterone differed considerably from that of rotenone, a 'classic' and specific inhibitor of cell respiration. Rotenone at $60 \mathrm{nmol} / \mathrm{l}$ caused the same decrease in

\section{C}

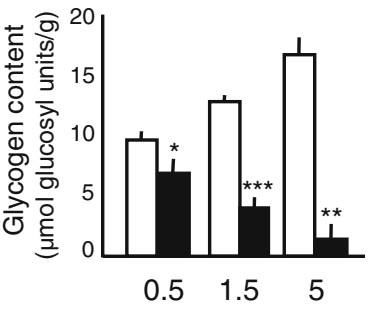

Total exposure time $(\mathrm{h})$ d

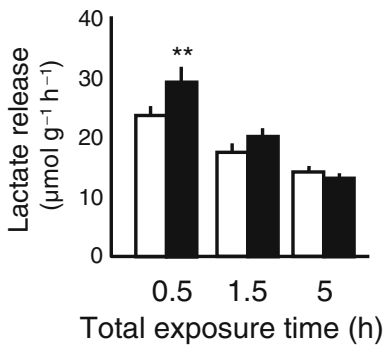

(during last $20 \mathrm{~min}$, when the total incubation period was only $0.5 \mathrm{~h}$ ). Glycogen content was determined at the end of the experiment (c). Data are means \pm SEM; ${ }^{*} p<0.05 ;{ }^{* *} p<0.01 ; * * * p<0.001$ vs absence of progesterone

glucose oxidation as $10 \mu \mathrm{mol} / \mathrm{l}$ progesterone (both $-39 \%$; Fig. 3), but triggered several-fold larger compensatory increments in glucose transport and lactate release, while glycogen depletion was less pronounced (Fig. 3). These differences indicate that progesterone blunted the increase in cellular glucose uptake as usually seen in response to reduced cell respiration, which limited substrate availability for anaerobic glycolysis and increased the demand for glycogen-derived substrate. Taken together, the results thus implicate a dual effect of progesterone-inhibition of cell respiration in parallel with suppression of a compensatory increase in glucose uptake.

Time dependence Progesterone-induced reductions of net glycogen synthesis and glucose oxidation occurred very rapidly, within $30 \mathrm{~min}$, and almost the full amplitude of the response seen after $5 \mathrm{~h}$ was reached within the first $1.5 \mathrm{~h}$ (Fig. 4a,b). At variance with what was found after prolonged exposure, lactate release was increased after $30 \mathrm{~min}$ of exposure to $50 \mu \mathrm{mol} / \mathrm{l}$ progesterone, apparently because glycogen stores were not yet depleted and provided substrate for anaerobic glycolysis (Fig. 4c,d).

Progesterone action was rapid not only in occurrence, but also faded immediately after termination of continuous
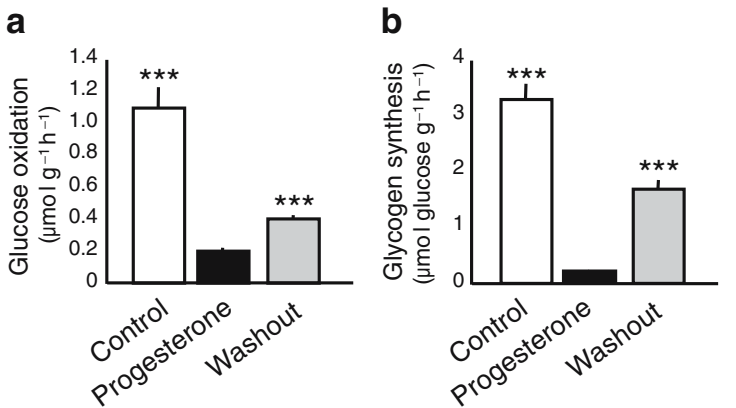

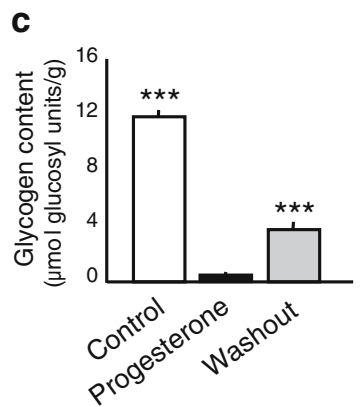

(b) were measured during the last hour under stimulation with $25 \mathrm{nmol} / 1$ insulin. Glycogen content was determined at the end of the experiment (c). Data are means \pm SEM; $* * * p<0.001$ vs $5 \mathrm{~h}$ continuous progesterone exposure 
exposure, as shown by relative increases in net glycogen storage and glucose oxidation after washout of progesterone only $15 \mathrm{~min}$ before the measurement period started (Fig. 5).

Interaction with inhibitors Since rapid occurrence and fading strongly hint at a non-genomic mode of action, we further examined dependence on genomic vs non-genomic mechanisms using established blockers of transcription (actinomycin D), protein synthesis (cycloheximide) and of the nuclear progesterone receptor, which is responsible for at least most genomic actions of the steroid (RU-486). No inhibitor counteracted the progesterone-induced impairment of muscle glucose metabolism, which excludes a genomic mechanism of action (Fig. 6).

Comparison with other steroids Several other steroids were tested under the same experimental conditions as progesterone. At a concentration of $50 \mu \mathrm{mol} / 1$, all of them affected

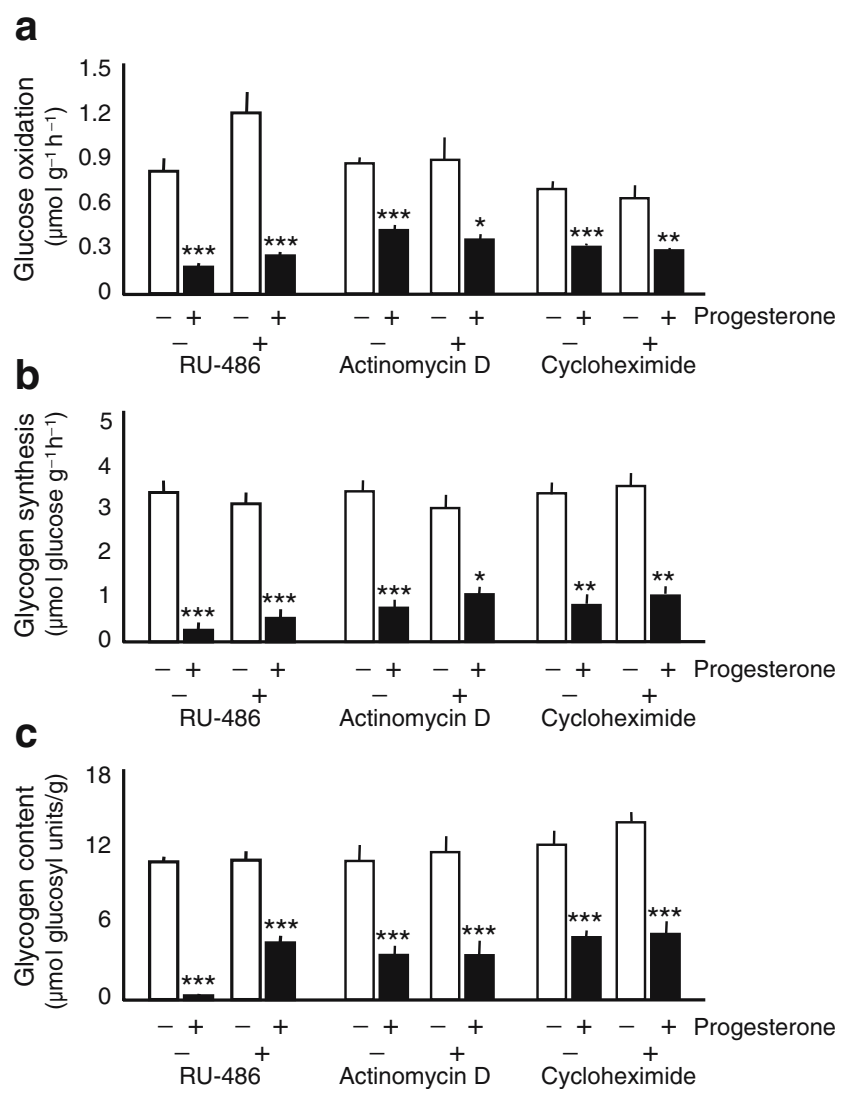

Fig. 6 Interaction of progesterone with pharmacological inhibitors. Strips of rat soleus muscle were incubated for $5 \mathrm{~h}$ without or with $50 \mu \mathrm{mol} / 1$ progesterone (open and closed bars, respectively), without or in combination with RU-486 $(10 \mu \mathrm{mol} / \mathrm{l})$, actinomycin D $(1 \mathrm{mg} / \mathrm{l})$ or cycloheximide $(1 \mathrm{mg} / \mathrm{l})$. Rates of glucose oxidation (a) and net glycogen synthesis (b) were measured during the last hour under stimulation with $25 \mathrm{nmol} / \mathrm{l}$ insulin. Glycogen content was determined at the end of the experiment (c). Data are means \pm SEM; $* p<0.05$; ${ }^{* *} p<0.01 ; * * * p<0.001$ vs absence of progesterone
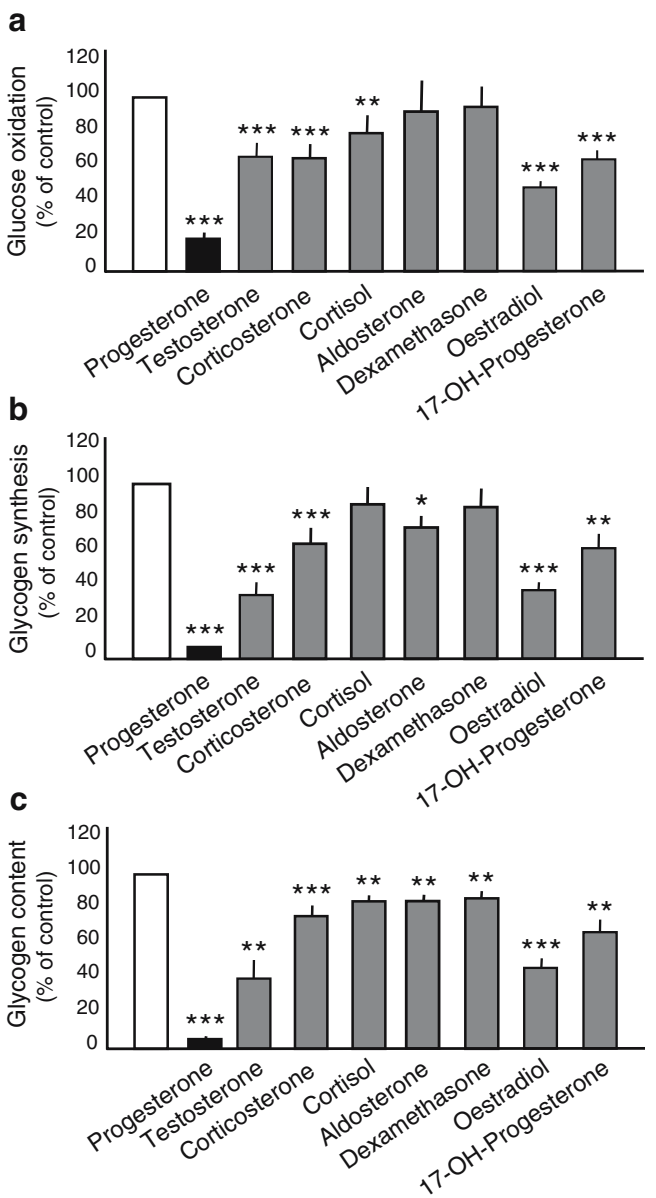

Fig. 7 Comparison of various steroids. Strips of rat soleus muscle were incubated for $5 \mathrm{~h}$ with $50 \mu \mathrm{mol} / \mathrm{l}$ of the indicated steroid. Rates of glucose oxidation (a) and net glycogen synthesis (b) were measured during the last hour under stimulation with $25 \mathrm{nmol} / 1$ insulin. Glycogen content was determined at the end of the experiment (c). Data are given as a percentage of an intra-individual control and as means \pm SEM; ${ }^{*} p<0.05 ;{ }^{* *} p<0.01 ; * * * p<0.001$ vs control $(=100 \%) .17-0 \mathrm{H}-$ Progesterone, 17-hydroxyprogesterone

glucose metabolism in a qualitative manner reminiscent of the effects exerted by progesterone. However, the amplitudes of the effects were less pronounced than with progesterone in the following ranking: progesterone $\gg$ testosterone $\approx$ oestradiol $>$ corticosterone $\approx 17$-OH-progesterone $>$ cortisol $\approx$ aldosterone $\approx$ dexamethasone (Fig. 7).

\section{Expression of Pgrmcl}

Progesterone receptor membrane component 1 , a putative cell-surface receptor for progesterone (or a part of it) is believed to mediate non-genomic actions in various cells [23-26]. Based on evidence for a non-genomic mode of action we determined if this putative receptor is expressed in rat skeletal muscle. In line with a previous study on pigs [27], Pgrmcl mRNA was found in liver and spleen, with a 
a

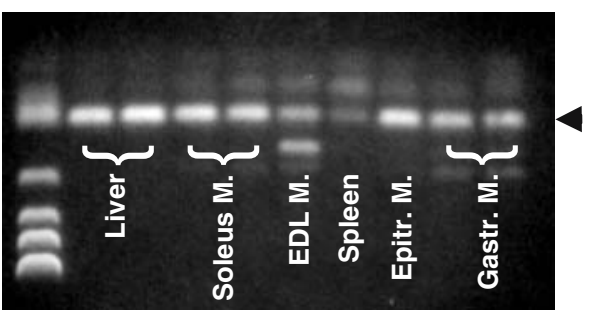

C

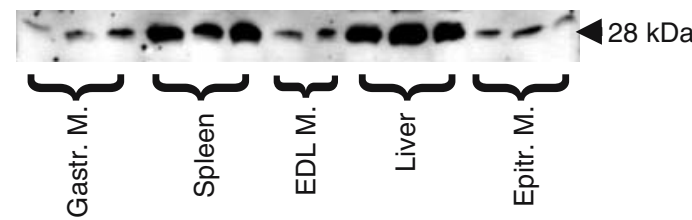

b

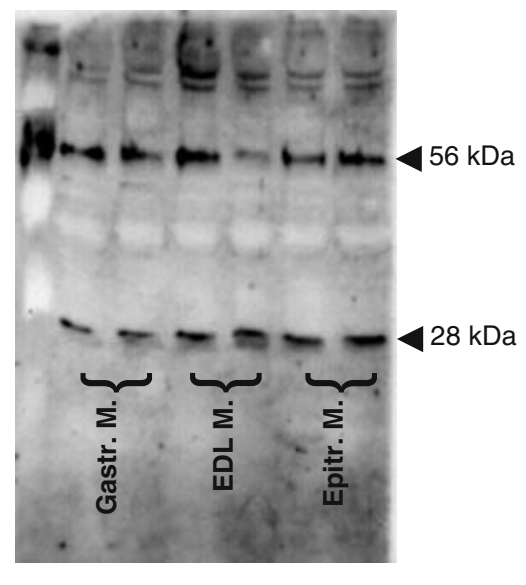

Fig. 8 Expression of Pgrmcl in rat tissues. a Expression of Pgrmcl mRNA in the indicated tissues obtained from male rats. The additional distinct band found in extensor digitorum longus muscle was analysed by VBC-Genomics. It was found to encode for a myosin component and to have no significant alignment with Pgrmcl. b, c Detection of

more intense signal obtained from liver samples (Fig. 8a). In addition, we show for the first time that Pgrmcl mRNA is expressed in rat skeletal muscles of various fibre composition (Fig. 8a). The corresponding progesterone receptor membrane component 1 protein $(28 \mathrm{kDa})$ was clearly detected by western blotting with both employed antibodies 7790 (Fig. 8b) and T2 (Fig. 8c).

\section{Discussion}

Although a direct effect of progesterone on skeletal muscle could explain many of the metabolic changes associated with late pregnancy, early evidence for the existence of such actions was not pursued $[10,16]$. The present study resumed this line of research and analysed the influence of progesterone on substrate fluxes through the various pathways of glucose metabolism. It is shown that progesterone, via a rapid and direct effect on rat skeletal muscle, shifts glucose flux from the aerobic into the anaerobic pathway, which indicates impaired cell respiration. Impairment of cell respiration usually triggers a compensatory increase in glucose transport to cover elevated fuel requirements for anaerobic ATP production [29, 30], but this response is markedly blunted under progesterone exposure. Such a combination of increased glucose demands with impaired recruitment of additional glucose necessarily results in a distinct shortage of intracellular carbohydrate availability. The consequences of cellular carbohydrate shortage in progesterone-exposed muscle strips include: (1) accelerated depletion of glycogen stores; (2) rates of lactate release that are obviously limited by substrate availability; and (3) a much more distinct reduction in $\mathrm{CO}_{2}$ production from glucose than from palmitate. the corresponding protein, progesterone receptor membrane component $1(28 \mathrm{kDa})$, by Western blot analysis. An additional band detected at $56 \mathrm{kDa}$ with antiserum 7790 (b) could be the protein dimer [28]. M., muscle; EDL, extensor digitorum longus; Epitr., epitrochlearis; Gastr., gastrocnemius

Without doubt, adaptations of glucose homeostasis during late pregnancy rely on the concerted actions of many hormones on many tissues, but our results appear readily compatible with the idea that direct progesterone action on skeletal muscle could make a relevant contribution. In isolated muscle, increased lactate release and reduced pyruvate oxidation were observed after exposure to $1 \mu \mathrm{mol} / \mathrm{l}$ progesterone, a concentration that is reached in plasma of pregnant women and rats [3, 4]. Hence, a surplus of lactate from skeletal muscle could contribute to elevated plasma concentrations as well as to increases in hepatic lactate uptake and in gluconeogenesis from lactate of pregnant rats [31, 32]. Furthermore, the described effects on glucose transport into muscle could obviously contribute to the gestational reduction in glucose disposal $[1,2]$. In summary, the picture thus fits with the proposed biological meaning of late gestational adaptations, which is to redirect carbohydrate flux from storage in maternal tissues towards availability for fetal development.

Regarding the mechanism of progesterone action, our findings leave not doubt that the described actions of progesterone are non-genomic. This is indicated by immediate occurrence and fading of the response as well as by its persistence under exposure to specific inhibitors of transcription, protein synthesis or of the 'classic' intracellular progesterone receptor. Although a relatively low concentration of $1 \mu \mathrm{mol} / \mathrm{l}$ progesterone was effective, we can not finally exclude an 'unspecific', i.e. receptor-independent, mechanism of action. However, findings reported by others suggest that progesterone can trigger non-genomic effects via proteins that are located in the plasmalemma and function as receptors $[13,25,33,34]$. In line with putative signal transduction via a cell-surface receptor, a relatively low concentration of BSA-coupled progesterone, which is 
unable to enter the cell, induced a trend to reduced net glycogen synthesis in our experimental setting $(p=0.051$; ESM Fig. 2).

So far, the search for cell-surface receptors for progesterone has suggested two candidate proteins, one of which is not expressed in human skeletal muscle and is therefore unlikely to mediate the effects described here [33]. The second candidate, referred to as progesterone receptor membrane component 1 , is believed to be implicated in various rapid non-genomic effects of progesterone including the modulation of apoptosis in granulosa and luteal cells [26] and the induction of $\mathrm{Ca}^{2+}$ fluxes and the acrosome reaction in sperm $[24,25]$. We show for the first time that this putative receptor is expressed in rat skeletal muscle and is therefore available for signal transduction. Furthermore, the hierarchy of several steroids as mimickers of progesterone action in isolated muscle has noticeable parallels with their presumptive binding affinities to progesterone receptor membrane component 1 (progesterone 》 testosterone $\approx$ oestradiol $>$ corticosterone $>$ cortisol $\geq$ aldosterone $\approx$ dexamethasone) $[24,28]$. An exception in this regard is oestradiol, which is relatively more effective in muscle, but distinct non-genomic actions ascribed to oestradiol and evidence for oestrogen receptors located directly on mitochondria raise the possibility that this particular steroid affects muscle metabolism via its own specific pathway [13, 35]. Although final conclusions can not be drawn at this stage, our results are at least compatible with the idea that progesterone receptor membrane component 1 could be the mediator of the observed effects.

In summary, we show that progesterone acts directly on rat skeletal muscle via a rapid non-genomic mechanism that impairs cell respiration and at the same time suppresses a compensatory increase in glucose transport. The results are compatible with a possible contribution of this mechanism to the characteristic changes in carbohydrate metabolism seen during late pregnancy.

Acknowledgements We thank R. Lösel, University of Heidelberg (Germany), for providing antibodies and for analytical advice. We thank the staff at the Core Unit for Biomedical Research, Medical University of Vienna, for taking care of the rats.

Duality of interest The authors declare that there is no duality of interest associated with this manuscript.

\section{References}

1. Hay WW (1998) Pregnancy, metabolic changes in. In: Knobil E, Neill JD (eds) Encyclopedia of reproduction, vol. 3. Academic, London, pp 1016-1026

2. Kühl C (1998) Etiology and pathogenesis of gestational diabetes. Diabetes Care 21(Suppl 2):B19-B26
3. Albrecht ED, Pepe GJ (1998) Placental steroidogenesis in primate pregnancy. In: Knobil E, Neill JD (eds) Encyclopedia of reproduction, vol 3. Academic, London, pp 889-898

4. Pepe GJ, Rothchild I (1974) A comparative study of serum progesterone levels in pregnancy and various types of pseudopregnancy in the rat. Endocrinology 95:275-279

5. Escalante Pulido JM, Alpizar Salazar M (1999) Changes in insulin sensitivity, secretion and glucose effectiveness during menstrual cycle. Arch Med Res 30:19-22

6. Valdes CT, Elkind-Hirsch KE (1991) Intravenous glucose tolerance test-derived insulin sensitivity changes during the menstrual cycle. J Clin Endocrinol Metab 72:642-646

7. Picard F, Wanatabe M, Schoonjans K, Lydon J, O’Malley BW, Auwerx J (2002) Progesterone receptor knockout mice have an improved glucose homeostasis secondary to $\beta$-cell proliferation. Proc Natl Acad Sci U S A 99:15644-15648

8. Shamma FN, Rossi G, HajHassan L et al (1995) The effect of Norplant on glucose metabolism under hyperglycaemic hyperinsulinemic conditions. Fertil Steril 63:767-772

9. Elkind-Hirsch KE, Sherman LD, Malinak R (1993) Hormone replacement therapy alters insulin sensitivity in young women with premature ovarian failure. J Clin Endocrinol Metab 76:472-475

10. Sutter-Dub M-T, Dazey B, Vergnaud M-T, Madec A-M (1981) Progesterone and insulin resistance in the pregnant rat. Diabetes Metab 7:97-104

11. Batista MR, Smith MS, Snead WL, Connolly CC, Lacy DB, Moore MC (2005) Chronic estradiol and progesterone treatment in conscious dogs: effects on insulin sensitivity and response to hypoglycaemia. Am J Physiol 289:R1064-R1073

12. Catalano PM, Tyzbir ED, Wolfe RR et al (1993) Carbohydrate metabolism during pregnancy in control subjects and women with gestational diabetes. Am J Physiol 264:E60-E67

13. Sutter-Dub M-T (2002) Rapid non-genomic and genomic responses to progestogens, estrogens, and glucocorticoids in the endocrine pancreatic B cell, the adipocyte and other cell types. Steroids 67:77-93

14. Gomez-Munoz A, Hales P, Brindley DN, Sancho MJ (1989) Rapid activation of glycogen phosphorylase by steroid hormones in cultured rat hepatocytes. Biochem J 262:417-423

15. Sutter-Dub MT, Kaaya A, Sfaxi A, Sodoyez-Goffaux F, Sodoyez JC, Sutter BC (1988) Progesterone and synthetic steroids produce insulin resistance at the post-receptor level in adipocytes of female rats. Steroids 52:583-608

16. Leturque A, Hauguel S, Sutter-Dub M-T, Maulard P, Girard J (1989) Effects of placental lactogen and progesterone on insulin stimulated glucose metabolism in rat muscles in vitro. Diabetes Metab 15:176-181

17. Crettaz M, Prentki M, Zanietti D, Jeanrenaud B (1980) Insulin resistance in soleus muscle from obese Zucker rats. Involvement of several defective sites. Biochem J 186:525-534

18. Brunmair B, Gras F, Neschen S et al (2001) Direct thiazolidinedione action on isolated rat skeletal muscle fuel handling is independent of peroxisome proliferator-activated receptor- $\gamma$ mediated changes in gene expression. Diabetes 50:2309-2315

19. Cuendet GS, Loten EG, Jeanrenaud B, Renold AE (1976) Decreased basal, noninsulin-stimulated glucose uptake and metabolism by skeletal soleus muscle isolated from obese-hyperglycemic $(o b / o b)$ mice. J Clin Invest 58:1078-1088

20. Engel P, Jones J (1978) Causes and elimination of erratic blanks in enzymatic metabolite assays involving the use of $\mathrm{NAD}^{+}$in alkaline hydrazine buffers: improved conditions for the assay of L-glutamate, L-lactate, and other metabolites. Anal Biochem 88: 475-484

21. Lowry OH, Passoneau JV (1972) A flexible system of enzymatic analysis. Academic, New York and London, pp 151-156 
22. Krebs M, Brunmair B, Brehm A et al (2007) The mammalian target of rapamycin pathway regulates nutrient-sensitive glucose uptake in man. Diabetes 56:1600-1607

23. Waldegger S, Beisse F, Apfel H et al (1995) Electrophysiological effects of progesterone on hepatocytes. Biochim Biophys Acta 1266:186-190

24. Falkenstein E, Heck M, Gerdes D et al (1999) Specific progesterone binding to a membrane protein and related nongenomic effects on $\mathrm{Ca}^{2+}$-fluxes in sperm. Endocrinology 140:5999-6002

25. Blackmore PF, Neulen J, Lattanzio F, Beebe SJ (1991) Cell surface-binding sites for progesterone mediate calcium uptake in human sperm. J Biol Chem 266:18655-18659

26. Peluso JJ, Pappalardo A, Lösel R, Wehling M (2006) Progesterone membrane receptor component 1 expression in the immature rat ovary and its role in mediating progesterone's antiapoptotic action. Endocrinology 147:3133-3140

27. Falkenstein E, Meyer C, Eisen C, Scriba PC, Wehling M (1996) Full-length cDNA sequence of a progesterone membrane-binding protein from porcine vascular smooth muscle cells. Biochem Biophys Res Commun 229:86-89

28. Meyer C, Schmid R, Scriba PC, Wehling M (1996) Purification and partial sequencing of high-affinity progesterone-binding site (s) from porcine liver membranes. Eur J Biochem 239:726-731
29. Brunmair B, Staniek K, Gras F et al (2004) Thiazolidinediones, like metformin, inhibit respiratory complex I. A common mechanism contributing to their antidiabetic actions? Diabetes 53:1052-1059

30. Hayashi T, Hirshman MF, Fujii N, Habinowski SA, Witters LA, Goodyear LJ (2000) Metabolic stress and altered glucose transport. Activation of AMP-activated protein kinase as a unifying coupling mechanism. Diabetes 49:527-531

31. Valcarde C, Cuezva JM, Medina JM (1985) Increased gluconeogenesis in the rat at term gestation. Life Sci 37:553-560

32. Rémésy C, Demigné C (1986) Adaptation of hepatic gluconeogenesis and ketogenesis to altered supply of substrates during late pregnancy in the rat. J Dev Physiol 8:195-205

33. Zhu Y, Bond J, Thomas P (2003) Identification, classification, and partial characterization of genes in humans and other vertebrates homologous to a fish membrane progestin receptor. Proc Natl Acad Sci USA 100:2237-2242

34. Rae MT, Menzies GS, McNeilly AS, Woad K, Webb R, Bramley TA (1998) Specific non-genomic, membrane-localized binding sites for progesterone in the bovine corpus luteum. Biol Reprod 58:1394-1406

35. Yang S-H, Liu R, Perez EJ et al (2004) Mitochondrial localization of estrogen receptor $\beta$. Proc Natl Acad Sci USA 101:4130 4135 